\title{
How Does the Attitude to Sustainable Food Influence the Perception of Customers at the Point of Sale? - an Eye-Tracking Study
}

\author{
Julia Lamberz \\ Osnabrück University of Applied Sciences, Faculty of Management, Culture \\ and Technology (Lingen Campus), Germany \\ Thorsten Litfin \\ Osnabrück University of Applied Sciences, Faculty of Management, Culture \\ and Technology (Lingen Campus), Germany \\ Özlem Teckert \\ Osnabrück University of Applied Sciences, Faculty of Management, Culture \\ and Technology (Lingen Campus), Germany \\ Gunther Meeh-Bunse \\ Osnabrück University of Applied Sciences, Faculty of Management, Culture \\ and Technology (Lingen Campus), Germany
}

\begin{abstract}
Sustainability is a growing megatrend in our society entailing an increasing importance of sustainable consumption. Consumers associate sustainable products with ecological and regional production including a high credibility. In order to take advantage of this trend manufacturers of sustainable foods must communicate the sustainability of their products via packaging and displays at the point of sale. The objective of this article is to examine how the design of display elements succeeds in conveying sustainability for a new organic juice. In addition, the perception of individual design elements of sustainable products is determined. To this end, a field study was carried out in a supermarket combining eye-tracking technology with a survey of 32 customers. At the entrance, customers were asked to buy a variety of the newly introduced "Emsländer" organic juice, and then participate in the survey. The results demonstrate that customers with a positive attitude towards sustainable food fixate individual display elements referring to sustainability components for longer and remember product features better. Hence, the positive attitude towards sustainable food results in a higher visual attention at the point of sale. These findings provide recommendations for the design of the display.
\end{abstract}

Keywords: consumer behaviour, eye-tracking, sustainability, visual merchandising, visual attention

JEL classification: M31, M37

Acknowledgments: Special thanks to Alexander Urmersbach, Research Assistant at Osnabrueck University of Applied Sciences.

\section{Introduction}

Sustainability is one of the megatrends that are gaining ground in our society. Accordingly, the importance of consuming sustainable products such as food is constantly growing. Within these niche sectors for sustainable food, sales in Germany 
grew by 15 percent in 2017 and reached single-digit billion figures (Fairtrade Deutschland, 2017). However, from the customer's point of view there is no clear definition of the term "sustainable food", as this term currently diversifies into many properties such as ecological regional production and no artificial additives (Aiking et al., 2004; Grunert, 2011; von Meyer-Höfer, 2016). Von Meyer-Höfer surveyed 570 consumers in Germany and Switzerland on the properties of sustainable foods. According to the survey, consumers expect sustainable foods to have ecological, regional, ethical and social properties. Since these properties have only a limited impact on taste and appearance, they cannot be clearly linked to food. It is therefore difficult for consumers to recognise sustainable product properties at the point of sale (von Meyer-Höfer, 2016). Producers and sellers of sustainable foods may communicate the sustainability of their products via packaging and displays at the point of sale to pick up on the trend towards sustainability and use it for their own benefit.

The objective of this article is to demonstrate how the design of displays can influence the visual perception of sustainable foods at the point of sale. To this end visual perception and shopping behaviour at the point of sale as well as the potential of applying eye-tracking approaches will be examined from a theoretical point of view. Building on this, the extent to which the design of individual display elements succeeds in visually communicating sustainability will then be examined for a new sustainable organic juice. The significance of sustainability for customers will also be determined. Furthermore, extent to what this significance is related to the perception of individual display elements are in the research focus. For this purpose, the use of eye-tracking technology will be combined with a questionnaire.

\section{Visual perception and purchasing behaviour at the point of sale}

To assess how products and brands influence the purchase decision at the point of sale, the analysis of customer perception is important (Pieters et al., 1999). Products are viewed with the eye of a customer and the brain processes the perceived images. This visual cognitive processing consists of a series of stops (fixations) and jumps (saccades) (Russo, 1978). Simultaneously, the product fixation processes the information top-down and bottom-up. Consumers are not only influenced by externally perceived stimuli such as the colour design of product packaging and displays (bottom-up factors) but also by internal stimuli such as individual goals, product settings and memories (top-down factors). Some stimuli are expected and foreseen and the inner stimuli affects the perception and evaluation of external stimuli (Wedel et al., 2008).

The design of these external stimuli is of particular importance since about 65 percent of decisions are made spontaneously during the shopping process. The consumer only decides for half of his or her purchases based upon previous knowledge about a particular category or brand (Häusel, 2016). In addition, consumers have a decreasing amount of time to shop. As a consequence, the viewing times of product packaging are in a range of a few seconds (Pieters et al., 1999; Huddleston et al., 2015). During this time, $90 \%$ of all purchasing decisions are made by taking a quick look at the front of the product packaging (Grunert, 2011).

As a consequence, consumers make decisions with their eyes and buy the products they see (Nordfält, 2011). At the same time, consumers can be influenced by many factors while shopping. In addition to the wide range of products on offer, the purchasing decision is influenced by the design of the sales room, the presentation of the goods on displays and the product packaging (Gröppel-Klein, 2007). In an eyetracking study at the point of sale, Clement et al. (2013) identified the elements on 
packaging influencing the purchase decision. Based upon these insights they proposed a packaging design with simple features in order to achieve an increased probability of initial attention. Ultimately, this attention also has a positive influence on the purchase decision. For producers this means not only placing the goods in such a way that they are perceived and found by the consumer but also that packaging and displays are designed to be simple and target-group-oriented as an important point of contact to the customer (Huddleston et al., 2015).

\section{Eye-Tracking Studies}

Whether and for how long individual elements of displays and packaging are perceived can be measured by using eye-tracking methods (Duchowski, 2007). While many eye-tracking studies were carried out at the laboratory to examine product packaging (Huddleston et al., 2018), there are only a few studies that were realised in a regular shopping environment. Eye-tracking studies at the point of sale demonstrated that individual display and packaging elements have an influence on visual attention, search and buying intention (Clement et al., 2013; Huddleston et al., 2015). Laboratory studies analysing the perception of packaging demonstrated that the logo and images attracted attention, while the product name had little impact (Wästlund et al., 2018; Choloewa-Wójcik et al., 2015). During an eye-tracking laboratory study van Loo et al. (2015) examined not only the perception of individual packaging elements but also relationships between consumers' attitudes to individual sustainability attributes and the visual perception of sustainability labels. The results confirmed that the importance of sustainability attributes for visual attention is relevant (van Loo et al., 2015). Consumers who associate individual packaging elements (labels) with sustainability have a higher probability of buying this product, and they also place more trust in it (Samant et al., 2016). To measure the perception of individual labels, logos and images, the authors correlated the eye-tracking metrics "total fixation duration" and "total fixation count" (Samant et al., 2016; Huddleston et al., 2015; van Loo et al., 2015; Clement et al., 2013). In addition to bottom-up factors (sustainability labels, label information), van Loo et al. (2015) and Samant et al. (2016) also incorporated top-down factors (label knowledge, attitude towards sustainability attributes). These factors are considered to influence perception according to the theory of Wedel et al. (2008).

\section{Methodology}

The objective of this study is to examine the extent to which the design of individual display elements succeeds in visually conveying sustainability aspects for a newly introduced sustainable organic juice. In doing so, the perception in a regular shopping environment is in focus. Both bottom-up factors (display elements) and top-down factors (attitude towards sustainable food, memory) are put in relationship to each other (Wedel et al., 2008). In addition, the extent to which consumers consider this organic juice as a sustainable foodstuff is examined. Moreover, the question is asked whether or not consumers remember the display elements that should visualise the sustainability dimensions. Furthermore, differences in behaviour between customers with a positive or less open-minded attitude towards sustainable food were in the focus. The following research questions are of particular interest:

a) Perception: Do consumers perceive those display elements that visualize the sustainability of the organic juice on the display? Do consumers with a positive attitude towards sustainable food look longer at these display elements? 
b) Memory: Can consumers remember the elements that visualize the sustainability of the organic juice on the display? Do consumers with a positive attitude towards sustainable food remember these display elements better?

In order to answer these questions eye-tracking technology was combined with a survey. For this purpose, a total of 32 consumers were recruited before shopping in a supermarket in the town of Nordhorn (Lower Saxony, Germany). A total of 17 females (10 aged not older than 50 years) and 15 males (9 aged not older than 50 years) participated in the study. All participants were rewarded with a $5 €$ gift voucher from the supermarket. At first, the test persons were informed about the course of the study, and they were asked to provide information on socio-demographic characteristics (age and gender) as well as their assessment of sustainability aspects. Based on the results of von Meyer-Höfer (2016), the importance of the sustainability aspects "regionality", "ecological production", "socially committed company" and sustainable product was asked on a five-step Likert scale (from "agree" to "disagree"). In the second place, the test persons were given the task of buying the organic juice "Emsländer", whereby the purchasing area was limited to the vegetable department of the supermarket. The test subjects' eye movements were recorded during the shopping process with the help of "Tobii Pro Glasses 2" eye-tracking glasses. The individual design elements of the display were defined as areas of interest (AOI) to communicate the sustainability of the organic juice. The visual attention was captured with the eye-tracking metric "total fixation duration" of this AOls. In the third place, the test persons were asked to answer questions about their memory of pictures, slogans and place of production on the display and the juice bottle on a five-step Likert scale ("I fully agree" to "I do not agree at all") (see table 2). The task was to detect: (1) whether consumers with a positive attitude towards sustainable food gave the display elements at the point of sale greater visual attention and (2) consumers remember the design elements of the display better. For this reason, the "total fixation duration" of AOls was related to the survey results by means of mean value comparisons (table $1+2)$.

\section{Results}

The methodology described above was successful in answering the questions. The display was divided into a total of 6 AOls visualizing the sustainability aspects described above (figure 1). A total of 25 out of 32 participants noticed the display. The analysis of the heat map in Figure 1, which displays the intensity with which the test persons looked at the individual AOls, confirms a clear focus of the glances at the image "three bottles", the headline 1 with the brand name "Emsländer", the advertising slogan "local berries" and the picture 1 with "Apples, currants and bilberries".

In order to verify whether consumers with a positive attitude towards sustainable food looked longer at individual display elements, the questions on the importance of the component's "regionalism", "ecological production", "sustainable product" and "social company" were first combined into a construct "sustainability as a whole". The corresponding Cronbach alpha value of .802 indicates a high internal consistency of this construct. Based on the overall sustainability construct, the test persons were divided into two groups: "sustainability important" and "sustainability unimportant". The group separation was carried out on a scale of 5 (agree (1.00) to disagree (5.00) at a value of 2.00. There are no substantial and significant differences in gender. There was no further group separation regarding the different age intervals due to the low sample size. The mean values of the two groups of respondents "sustainability important" ( $n=15)$ and "sustainability unimportant" $(n=17)$ were then compared in relationship to the individual AOls. Due to the low sample size, the eye-tracking metrics 
only show a tendency towards a stronger consumers' perception of individual images, slogans and headlines with a positive attitude towards sustainable food. Heading 2 with the slogan "Superfood Blend of Berry Juice", which is intended to express both the special character of the drink and a possible area of use as a mixed drink, is considered less intensively. The same applies to picture 2 with the fruits "elderberry, currant, blueberry". Overall, the lower part of the display, which is no longer at eye level of the test persons, is viewed less intensely.

Figure 1

Areas of Interests (Aois) (Left) and Heat Map (Right) of the Poster on Display

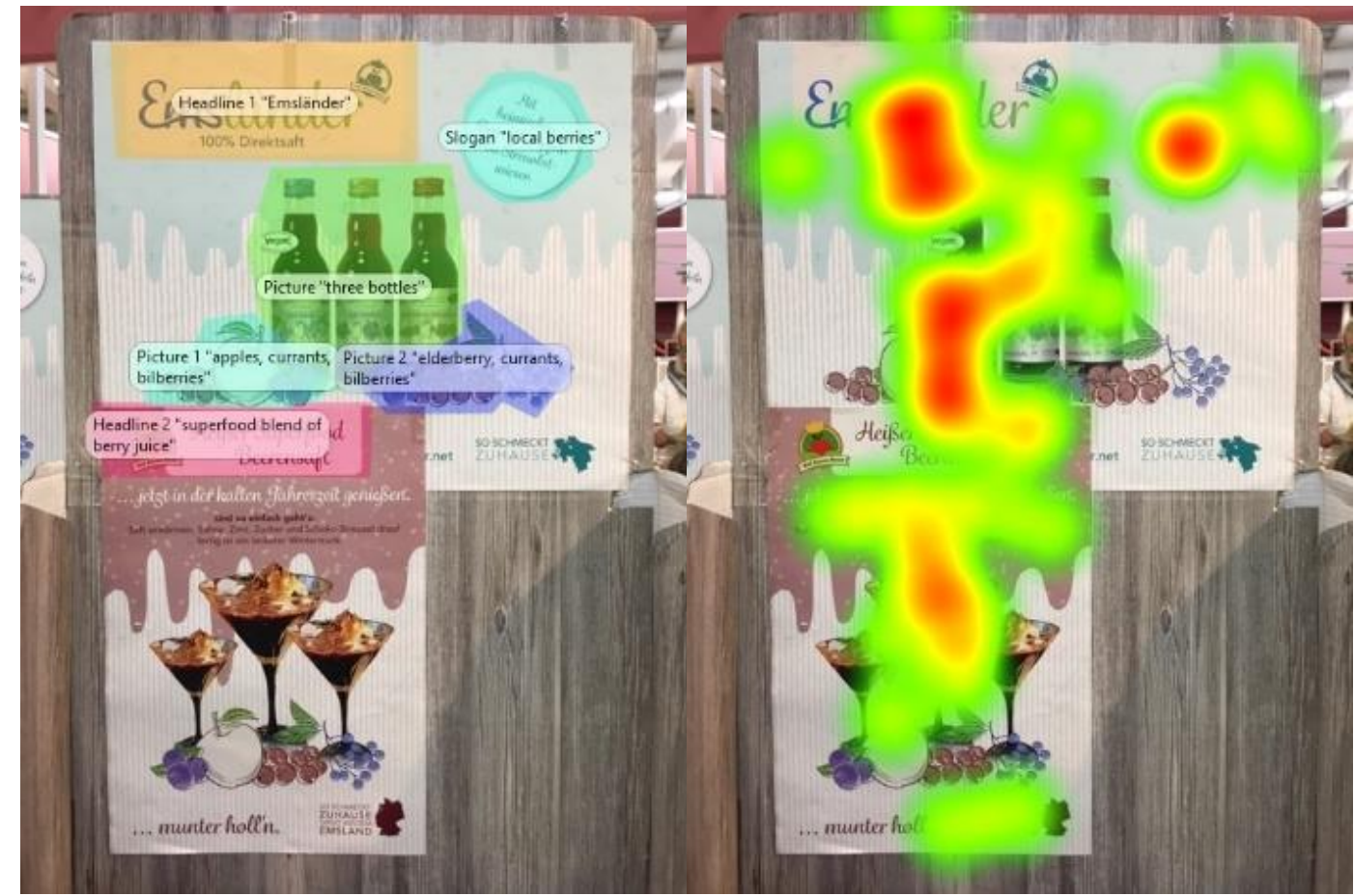

Note: left: representation of the 6 AOls, right: total duration is calculated by the duration of fixations, whereas the warmest colour represents the highest value.

Source: Authors' illustration

Table 1

Total Fixation Duration (Average): Poster of Display (Frontal)

\begin{tabular}{llrlr}
\hline Total fixation duration (in sec./incl. zeros) & \multicolumn{3}{c}{ display „Poster frontal" } \\
\cline { 2 - 5 } & \multicolumn{2}{c}{$\begin{array}{c}\text { Sustainability } \\
\text { important }\end{array}$} & $\begin{array}{c}\text { Sustainability } \\
\text { unimportant }\end{array}$ \\
AOI & Mean & SD & Mean & SD \\
\hline Picture "three bottles" & $1.36^{*}$ & 2.19 & $0.44^{* *}$ & 0.50 \\
\hline Slogan "local berries" & $0.33^{*}$ & 0.75 & $0.09^{* *}$ & 0.35 \\
\hline Headline 1 "Emsländer" & $0.28^{*}$ & 0.54 & $0.18^{* *}$ & 0.39 \\
\hline Headline 2 "Superfood blend of berry juice" & $0.18^{*}$ & 0.36 & $0.25^{* *}$ & 0.80 \\
\hline Picture 1 "apples, currants, bilberries" & $0.18^{*}$ & 0.43 & $0.06^{* *}$ & 0.15 \\
\hline Picture 2 "elderberry, currants, billberries" & $0.04^{*}$ & 0.10 & $0.04^{* *}$ & 0.15 \\
\hline All & $0.39^{*}$ & $\mathbf{0 . 5 5}$ & $\mathbf{0 . 1 8 ^ { * * }}$ & $\mathbf{0 . 3 3}$ \\
\hline
\end{tabular}

Note: Total fixation duration (average) in seconds to $\mathrm{AOI}$ (include zeros)

*picture $n=10$, slogan $n=4$, headline $1 n=6$, headline $2 n=5$, picture $1 n=4$, picture $2 n=2$, all $n=12$ ${ }^{* *}$ picture $n=12$, slogan $n=2$, headline $1 n=6$, headline $2 n=3$, picture $1 n=4$, picture $2 n=2$, all $\mathrm{n}=13$,

Source: Authors' work 
The results demonstrate that the "sustainability important" group looked at AOls for a longer time (average of $0.39 \mathrm{sec}$ ). Not all test persons looked at the defined AOls. As a result, a tendency towards a stronger perception of individual AOls of the "sustainability important" group can be demonstrated. A total of 22 test persons looked at the picture "three bottles". Exactly 10 test persons of the group "sustainability important" fixed the $\mathrm{AOI}$ with an average of $1.36 \mathrm{sec}$. This indicates a stronger perception. Heading 2 was fixed by the group "sustainability unimportant" at $0.25 \mathrm{sec}$. On average, this is for a longer period of time by all AOls, whereby the sample of 3 test persons is notably small (table 1).

The memories of the special features of the newly introduced organic juice are well (2.00) to moderately (3.41) among all test persons. A comparison of the two groups of respondents shows that the "sustainability important" group remembered individual display elements better (overall 2.27) than the "sustainability unimportant" group (2.93) (see table 2). On average, the "sustainable important" group was also able to remember more distinct images. The mean values of comparison also demonstrate a significant difference between the two groups "sustainability important" (2.00) and "sustainability unimportant" (3.12) with regard to the memory of images on the packaging of the organic juice. Due to the small sample size none of the other mean value comparisons revealed significant differences between the two groups. The results show that the group "sustainably important" can remember distinct display elements better than the other group (table 2).

Table 2

Perception of Particular Packaging and Display Elements

\begin{tabular}{lcccc}
\hline Questions & \multicolumn{2}{c}{$\begin{array}{c}\text { Sustainability } \\
\text { important }\end{array}$} & \multicolumn{2}{c}{$\begin{array}{c}\text { Sustainability } \\
\text { unimportant }\end{array}$} \\
\hline What you can remember? & Mean & SD & Mean & SD \\
I know what makes the juice special. & 2.27 & 1.16 & 3.00 & 1.36 \\
I remember the images on the juice bottle. & $2.00^{*}$ & 1.00 & $3.12^{*}$ & 1.16 \\
I remember the images on the display. & 2.73 & 1.48 & 3.41 & 1.06 \\
| know where the juice is produced. & 2.07 & 1.28 & 2.18 & 1.07 \\
\hline All & $\mathbf{2 . 2 7}^{* *}$ & $\mathbf{0 . 8 3}$ & $\mathbf{2 . 9 3 ^ { * * }}$ & $\mathbf{0 . 7 7}$ \\
\hline
\end{tabular}

Note: Likert scale where $1=$ totally agree, $5=$ totally disagree

*t-Test: $p=0.007(p<0.05) \quad$ **t-Test: $p=0.028(p<0.05)$

Source: Authors' work

\section{Discussion}

This eye-tracking study at the point of sale has demonstrated that, in addition to bottom-up factors such as images, headlines and slogans on the display, top-down factors such as attitudes towards sustainable food also influence consumer perception. At the point of sale, the results indicate that consumers with a positive attitude towards sustainable food deal more intensively with the product information. The subsequent survey to remember individual elements on the juice bottle and the display confirms this. Due to the short observation period and orientation phase of consumers during shopping activities, the pictures and headlines on the display should be designed and placed in such a way that they achieve a high thematic significance.

The gaze recordings also confirm that images and headlines on the upper part of the display and at eye level with the consumer were perceived more intensely. Information, images and slogans on the lower poster were only perceived by a small number of consumers. For this reason, it is advisable to design the display with as little 
as possible text and images in order to achieve the highest possible initial attention at the point of sale (Clement et al., 2013). Therefore, the study provides for the manufacturer new approaches to the design of the display. The display should not be overloaded with so many topics that are ultimately not perceived and remembered. Rather focus should be concentrated even more on a few concise display elements that communicate sustainability.

\section{Conclusion}

The evaluation of the combined eye-tracking/survey study proved the fundamental suitability of this methodology for the analysis of display design for sustainable food in a supermarket (field study). Above all, the implementation within a pure natural purchasing situation provides a high validity based on the real situation on site.

This study at the point of sale can serve as a basis for further studies. Additional bottom-up factors such as shape and colour of individual elements of a display or product packaging could be analysed in order to detect why an element attracts attention and why it is better perceived and remembered (Huddleston et al., 2015). For example, an in-depth analysis may be useful to detect whether a sustainability aspect is visualised with a single element. One limitation of this eye-tracking study is the low number of samples. In particular, the eye-tracking metrics could not achieve a significant result due to fewer glances at individual AOls. This may change with a representative sample size.

In addition, other metrics, such as fixation counts, can be used to analyse perception (van Loo et al., 2015). The study was conducted in only one single supermarket. The inclusion of further supermarkets has the potential to indicate the effect of different designs of supermarkets and increase the number of respondents. Thus, this approach may help to provide more insights into the perception of the packaging and display of the organic juice by different target and age groups at the point of sale.

\section{References}

1. Aiking, H., de Boer, J. (2004), "Food sustainability. Diverging interpretations", British Food Journal, Vol. 106, No. 5, pp. 359-365.

2. Choloewa-Wójcik, A, Kawecka, A. (2015), "The influence of effectiveness of packaging elements on the consumers' preferences with the use of marketing eye-tracking technique", Modern Management Review, Vol. 20, No. 22(1), pp. 49-61.

3. Clement, J., Kristensen, T., Grønhaug, K. (2013), "Understanding consumers' in-store visual perception: The influence of package design features on visual attention", Journal of Retailing and Consumer Services, Vol. 20, No. 2, pp. 234-239.

4. Duchowski, A. T. (2007), Eye Tracking Methodology - Theory and Practice, Springer, London.

5. Fairtrade Deutschland (2017), "Jahres- und Wirkungsbericht 2017", available at: https://www.fairtradedeutschland.de/fileadmin/DE/mediathek/pdf/fairtrade transfair jahresbericht2017 web.pdf (26 March 2019).

6. Gröppel-Klein, A. (2007), "Konsumentenverhaltensforschung am Point-of-Sale", magazin forschung, Vol. 12, No. 2, pp. 14-19.

7. Grunert, K. G. (2011), "Sustainability in the Food Sector: A Consumer Behaviour Perspective", International Journal on Food System Dynamics, Vol. 2, No. 3, pp. 207-218.

8. Häusel, H.-G. (2016), Brainview - Warum Kunden kaufen, Freiburg, Haufe-Lexware.

9. Huddleston, P. T., Behe, B. K., Driesener, C., Minahan, S. (2018), "Inside-outside: Using eye-tracking to investigate search-choice processes in the retail environment", Journal of Retailing and Consumer Services, Vol. 43, pp. 85-93. 
10. Huddleston, P., Behe, B. K., Minahan, S., Fernandez, R. T. (2015), "Seeking attention: an eye tracking study of in-store merchandise displays", International Journal of Retail \& Distribution Management, Vol. 43, No. 6, pp. 561-574.

11. Nordfält, J. (2011), "Improving the attention-capturing ability of special displays with the combination effect and the design effect", Journal of Retailing and Consumer Services, Vol. 18, No. 3, pp. 169-173.

12. Pieters, R., Warlop, L. (1999), "Visual attention during brand choice: The impact of time pressure and task motivation", International Journal of Research in Marketing, Vol. 16, No. 1, pp. 1-16.

13. Russo, J. E., (1978), "Eye fixations can save the world: a critical evaluation and a comparison between eye fixations and other information processing methodologies", in Hunt, H. K. (Ed.), Advances in Consumer Research, Association for Consumer Research, Ann Arbor, Ml, pp. 561-570.

14. Samant, S. S., Seo, H. S. (2016), "Effects of label understanding level on consumers' visual attention toward sustainability and process-related label claims found on chicken meat products", Food quality and preference, Vol. 50, pp. 48-56.

15. Van Loo, E. J., Caputo, V., Nayga Jr, R. M., Seo, H. S., Zhang, B., Verbeke, W. (2015), "Sustainability labels on coffee: Consumer preferences, willingness-to-pay and visual attention to attributes", Ecological Economics, Vol. 118, pp. 215-225.

16. von Meyer-Höfer, M. (2016), "Erwartungen schweizerischer und deutscher Verbraucher an nachhaltige Lebensmittel", Journal of Socio-Economics in Agriculture, Vol. 9, pp. 113.

17. Wästlund, E., Shams, P., Otterbring, T. (2018), "Unsold is unseen ... or is it? Examining the role of peripheral vision in the consumer choice process using eye-tracking methodology", Appetite, Vol. 120, pp. 49-56.

18. Wedel, M., Pieters, R. (2008), "A review of eye-tracking research", in Malhotra, N. K. (Ed.), Review of marketing research, Emerald Group Publishing Limited, New York, pp. 123147.

\section{About the authors}

Julia Lamberz is currently a research assistant at Osnabrück University of Applied Sciences with a focus on marketing research. The author can be contacted at j.lamberz@hs-osnabrueck.de.

Thorsten Litfin is a Professor of Marketing, Service and Innovation Management at the Osnabrück University of Applied Sciences. His research interests include product and pricing strategies for innovative products and services. The author can be contacted at t.liffin@hs-osnabrueck.de.

Özlem Teckert is currently a research assistant at the Osnabrück University of Applied Sciences with a focus on marketing research. The author can be contacted at o.teckert@hs-osnabrueck.de.

Gunter Meeh-Bunse is a Professor of Finance and Accounting at the University of Applied Sciences at Osnabrück. His research interests include (non-) financial reporting and corporate social responsibility. The author can be contacted at g.meeh-bunse@hs-osnabrueck.de. 